\title{
0 tratamento dos registros linguísticos nas orientações e nos diálogos contidos em livros didáticos de italiano
}

\author{
The treatment of language styles in the guidelines and \\ dialogues contained in Italian textbooks
}

\author{
Graziele Altino Frangiotti ${ }^{1}$
}

\section{RESUMO}

Os livros didáticos ocupam papel central nas aulas de língua estrangeira, constituindo, muitas vezes, o principal material através do qual o aprendiz entra em contato com a língua alvo. Diante disso, nessa investigação, examinamos se e como os livros didáticos Linea diretta $e$ Rete!, empregados no ensino de italiano/LE no estado de São Paulo, tratam o continuum da formalidade. Para tanto, a partir de bibliografia pertinente (SOBRERO \& MIGLIETTA, 2008; COVERI et al., 1998; BELL, 1984), selecionamos 16 critérios relacionados à variação de registro e observamos sua presença e tratamento nos 102 diálogos contidos nas duas obras, bem como nas orientações presentes nos livros do aluno e nos guias do professor. Com base no conjunto de dados reunido, é possível dizer que os livros didáticos estudados não tratam suficientemente essa dimensão da variedade e que se limitam quase exclusivamente a explicações superficiais sobre o uso do pronome tu em situações informais e Lei em contextos formais.

Palavras-chave: ensino de italiano; livro didático; variedades diafásicas; registro linguístico.

1. Universidade Federal de Santa Catarina. Santa Catarina - Brasil. https://orcid.org/00000001-6087-7005. E-mail: grazielefrangiotti@gmail.com. 


\section{ABSTRACT}

Textbooks play a central role in foreign language classes, often constituting the main material through which the learner comes into contact with the target language. Therefore, in this investigation, we examined whether and how the textbooks Linea diretta and Rete!, used in teaching Italian/ FL in the state of São Paulo, deal with the continuum of formality. For this purpose, on the basis of relevant bibliography (SOBRERO\& MIGLIETTA, 2008; COVERI et al., 1998; BELL, 1984), we selected 16 criteria related to register variation and observed their presence and treatment in the 102 dialogues contained in the two textbooks, as well as in the guidelines present in the student's books and in the teacher's guides. Based on the set of data gathered, it is possible to say that the textbooks studied do not sufficiently deal with this dimension of variety and that they are almost exclusively limited to superficial explanations about the use of the pronoun tu in informal situations and Lei in formal contexts.

Keywords: italian teaching; textbook; diaphasic varieties; language style.

\section{Introdução}

As pesquisas científicas na área do ensino de língua materna no Brasil têm privilegiado há algum tempo a concepção de língua enquanto um conjunto de variedades em constante mudança, defendendo a difusão da perspectiva segundo a qual tanto variantes prestigiadas quanto estigmatizadas devem ser analisadas e descritas para serem transpostas e levadas à sala de aula de língua portuguesa.

Com a consolidação dessa ótica no campo acadêmico, passou a ser cada vez mais urgente a necessidade de a escola se atualizar em relação a essa concepção de língua, deixando de lado a "norma curta" (FARACO, 2008), isto é, uma visão de língua completamente idealizada e distante da realidade dos aprendizes, para dar cada vez mais espaço aos usos efetivamente encontrados nas produções linguísticas orais e escritas dos falantes brasileiros.

É, portanto, em decorrência desse processo, que hoje podemos encontrar relatos de experiências como os de Cyranka (2011) e Silva (2009), que mostram como o tratamento do português brasileiro com foco na variação pode promover o aumento da capacidade analítica dos aprendizes ao motivá-los a refletir não apenas sobre a importância da 
variedade de língua que já possuem, mas também sobre a necessidade de ampliarem o repertório linguístico para atuarem satisfatoriamente nos diversos domínios da vida social.

Direcionando essa discussão ao campo do ensino de italiano/LE, embora a noção de competência sociolinguística, introduzida por Dell Hymes na década de 1960, tenha contribuído para que se pensasse o papel do contexto e, por conseguinte, da adequação para o funcionamento da interação em língua estrangeira, é ainda pequeno o número de estudos que se dedicam à análise de como a variação tem sido apresentada nesse contexto de ensino específico.

De modo geral, a língua italiana é descrita por diversos estudiosos (SOBRERO; MIGLIETTA, 2007; D’ACHILLE, 2006; SANTIPOLO, 2002; CORTELAZZO, 2000; COVERI et al., 1998; BERRUTO, 1987) a partir de cinco eixos centrais de variação: 1) a variação diacrônica, que diz respeito à transformação da língua ao longo do tempo; 2) a variação diatópica, que se relaciona à mudança que a língua pode sofrer de acordo com o local em que é falada; 3) a variação diamésica: que contempla as características que a língua pode assumir em consequência do meio empregado na comunicação (o ar, o papel, o meio digital, etc.); 4) a variação diastrática: que está ligada às condições sócio-econômicas e culturais dos falantes; e, finalmente, 5) a variação diafásica: que se refere à situação comunicativa e aos objetivos do falante.

Diante dessa complexa arquitetura, partimos do pressuposto de que o aprendiz de língua italiana deva ser incentivado a entrar em contato com as diferentes dimensões da variação para que se torne cada vez mais apto a compreender e a produzir na língua estrangeira nos mais diferentes contextos que vier a atuar.

Tendo em vista a impossibilidade de abordar como todos esses eixos são levados à sala de aula de italiano/LE, optamos por nos dedicar, nesse trabalho, à diafasia. Para isso, com base nas obras de referência Sobrero e Miglietta (2007) e Coveri et al. $(1998)^{2}$, selecionamos 16

2. Como dito, muitas foram as obras que realizaram a análise das variedades da língua italiana, contudo, para os objetivos desse estudo, baseamo-nos em Sobrero e Miglietta (2007) e Coveri et al. (1998) por eles elencarem e descreverem de modo mais aprofundado os fenômenos marcados em diafasia, o que foi de grande auxílio para a investigação conduzida nos dois livros didáticos. 
critérios capazes de diferenciar o registro formal do informal e observamos se e como ocorre a inserção desses fenômenos nas coleções didáticas Linea diretta e Rete!, selecionadas a partir de uma sondagem que se baseou no envio de um questionário a 20 escolas do estado de São Paulo, por meio do qual perguntamos qual era o livro didático adotado nos cursos.

No que diz respeito à organização textual, este artigo se divide em três partes fundamentais, a saber: a) na primeira delas, apresentamos o conceito de registro linguístico, explicitando seu vínculo com as noções de monitoramento, audiência, ambiente e tópico (LABOV, 1975, 2008; BELL, 1984); b) na segunda parte, esclarecemos os passos metodológicos empreendidos, como o processo de seleção das coleções didáticas, a definição dos aspectos linguísticos analisados e os procedimentos adotados; e, finalmente, c) na última seção, discutimos os resultados obtidos.

\section{Os fatores ligados à variação de registro nas línguas naturais}

Parece ser um ponto pacífico na área da Linguística o fato de que a produção de um falante varia de um contexto comunicativo para outro. Apesar disso, falta ainda uma explicação unívoca que dê conta das razões que levam o falante a alterar a maneira de se expressar em resposta à situação na qual se encontra. Para exemplificar os diferentes posicionamentos quanto a essa questão, retomaremos, a seguir, as reflexões de Labov $(1975,2008)$ e Bell (1984).

Antes de tudo, é relevante salientar que a análise da variação linguística pode se dar a partir de uma perspectiva mais "social", ou seja, quando a interação é examinada com o objetivo de compreender a influência exercida pelo grupo social, pela classe socioeconômica, pela idade, pelo grau de escolaridade e pela região geográfica de proveniência do falante; ou a partir de uma perspectiva mais "individual", isto é, quando a observação é feita com o intuito de colocar em evidência como um mesmo falante modula sua própria produção verbal em diferentes contextos. 
Neste trabalho, estamos lidando justamente com a segunda perspectiva. Isso significa dizer que as reflexões propostas estão no âmbito daquela que foi denominada por Labov variação estilística ou, como denominada por Bagno et al. (2002), variação de registro ${ }^{3}$.

Debruçando-nos mais diretamente sobre os fatores que influenciariam a seleção de um determinado estilo, Labov considera que essa escolha seria fruto direto do monitoramento dispensado à produção linguística. Assim, quanto maior a atenção do falante, mais controlada é a fala e, por conseguinte, mais monitorada e formal ela se torna. Do mesmo modo, quanto menos planejado é o discurso, mais baixo será o grau de monitoramento linguístico e, logo, o de formalidade.

Em direção distinta, Bell (1984) separa os fatores que entrariam em jogo no momento da definição do estilo linguístico em duas subcategorias: os fatores relacionados à audiência e os não ligados a ela.

Em sua argumentação, Bell promove uma ampliação do conceito de audiência, incluindo não apenas as pessoas com as quais o falante efetivamente conversa, isto é, o interlocutor em sentido estrito (address $\mathrm{s}^{4}$ ); mas também terceiras pessoas, isto é, ouvintes que, mesmo presentes no contexto interacional, não se configuram como interlocutores, na medida em que os enunciados não se dirigem a eles.

Dentro dessa categoria de "terceiros", haveria três subcategorias: os ouvintes ratificados, ou seja, conhecidos pelo falante (auditors); os ouvintes casuais, que estão no contexto interacional, mas que não são ratificados pelo falante (overhearers); e os ouvintes cuja presença é totalmente desconhecida pelo falante (eavesdroppers).

De acordo com Bell, o interlocutor direto seria aquele que mais pressão exerceria no momento da definição do estilo, enquanto os "terceiros" influenciariam menos, em uma escala decrescente que vai dos ouvintes ratificados aos ouvintes desconhecidos.

3. Como os conceitos de estilo e registro, a nosso ver, não apresentam diferenças significativas entre si, eles serão aqui entendidos como sinônimos.

4. Como o texto não possui tradução para o português, optamos por explicar o significado dos termos, mas inseri-los, entre parênteses, como proposto na língua original. 
A premissa desse raciocínio seria a de que o falante, no anseio de receber aprovação do interlocutor, faria um movimento natural de convergência em direção a ele. Com isso, o seu estilo tenderia a refletir a imagem que faz da segunda pessoa com a qual interage. Haveria também casos em que o falante optaria por divergir de seu interlocutor, distanciando o seu estilo do dele. No entanto, essas ocorrências, para Bell, seriam menos frequentes e ocorreriam em decorrência de motivações específicas.

Para ilustrar o fenômeno da acomodação em direção ao interlocutor, o autor relembra que, em estudos em que se compara o estilo dos falantes em conversas com amigos ao estilo de quando interagem com pesquisadores em entrevistas, é comum que se verifique um grau maior de formalidade no segundo contexto. Para ele, isso revela que o informante avalia o estilo do interlocutor/pesquisador como mais próximo ao polo da formalidade e que, como consequência disso, conforma-se a ele, adotando um estilo mais formal.

Ainda com o intuito de mostrar como a acomodação funcionaria, Bell (1984) cita os trabalhos de Coupland (1980, 1981 e 1984), nos quais são observados e discutidos os estilos de fala de um funcionário de uma agência de turismo em interações com diferentes clientes. Na discussão final dos resultados, publicada em 1984, Coupland demonstra que o funcionário altera o estilo de acordo com as profissões desses clientes, ou melhor, de acordo com a classe social associada a essas profissões. Dessa maneira, com clientes que exercem profissões avaliadas como posicionadas na camada social mais baixa, o funcionário emprega um estilo mais informal, já com clientes que exercem atividades profissionais relacionadas às classes sociais mais altas, ele tende a empregar estilo mais formal.

Passando a se concentrar nos "terceiros", Bell recorre a trabalhos como o de Thelander (1982) e Bickerton (1980), por meio dos quais são feitas comparações do registro selecionado pelos falantes em duas situações: quando dialogam com amigos na ausência de um pesquisador e quando o pesquisador está presente, mas não participa da conversa.

A partir das análises realizadas, Thelander chega ao resultado de que os falantes aumentam a taxa de produção de fenômenos associados ao registro formal em $12 \%$ quando estão na presença de ouvintes 
ratificados. Já no trabalho de Bickerton, o percentual atinge $29 \%$, avançando a hipótese de que, de fato, a presença de ouvintes orientaria a seleção do registro, ainda que em menor grau se comparado ao papel do interlocutor direto.

Como dissemos, além dos fatores associados à audiência, haveria, segundo Bell (1984), o subgrupo dos elementos não relacionados a ela, que envolveria o tópico conversacional e o ambiente.

Sobre o primeiro deles, o estudioso retoma a investigação conduzida por Coupland (1981), em que se comparam as características da fala de um mesmo informante em interação com um mesmo grupo de pessoas, mas tratando de tópicos distintos - um mais pessoal e outro relacionado ao trabalho. O resultado das análises sugere que o estilo do informante investigado muda em resposta ao assunto abordado: tópicos relacionados ao trabalho levam-no ao emprego de registro formal, enquanto tópicos relativos à família, amigos e narrativa de experiências casuais propiciam o emprego de um registro mais informal.

Já sobre os efeitos do ambiente, Bell cita o estudo de Hindle (1979), que observa o discurso de uma pessoa em três situações diferentes: em casa, no escritório e durante a realização de um jogo. Após as análises, no entanto, Hindle conclui que a variação de estilo ocorreu como consequência da variação da audiência do falante e dos assuntos tratados, não sendo necessariamente fruto da mudança de ambiente.

Com os resultados das pesquisas levantadas, Bell se mostra convencido de que é impossível falar de mudança de registro sem se pensar na pressão causada pela audiência. Para ele, mesmo que outros fatores possam eventualmente entrar em jogo, como o tópico conversacional e o ambiente, é praticamente impossível dissociar estilo de audiência.

Alinhados a essa visão, diversos estudiosos no Brasil têm afirmado que a variação de registro é o resultado de forças contextuais, como o interlocutor, o ambiente e o tópico da conversa (BORTONI-RICARDO, 2004, 2005; BAGNO, 2007). Juntamo-nos a esses pesquisadores, porém, ampliando a noção de interlocutor para aquilo que Bell chamou audiência, uma vez que, a nosso ver, também ouvintes não envolvidos diretamente na interação podem desempenhar papel de destaque na seleção do registro linguístico. 
Nessa ótica, o falante, após fazer a leitura de sua audiência, decidiria se convergir ou divergir em relação a ela e se monitorar ou não aquilo que diz ou escreve. Somente a partir dessas ações ele definiria o estilo, selecionando estruturas congruentes com esse objetivo.

Se a seleção de um registro envolve todos esses diferentes fatores, então é de se esperar que, durante o ensino de uma língua estrangeira, sejam previstas atividades que não apenas fomentem discussões sobre esses aspectos contextuais, mas também que preparem o aprendiz para ter recursos linguísticos para operar com a variação.

Nessa direção, tendo em vista a importância assumida pelos livros didáticos no processo de difusão e ensino de línguas estrangeiras, partimos do pressuposto de que seria fundamental que as coleções introduzissem elementos relativos ao continuum da formalidade, incluindo entre suas atividades e orientações informações acerca dos fatores que podem determinar o registro empregado pelo falante, bem como explicações acerca de fenômenos associados a essas variedades.

No caso específico da língua italiana, acreditamos que a análise de livros como Linea diretta e Rete!, que foram e ainda são largamente utilizados em território brasileiro, sobretudo, em instituições privadas ${ }^{5}$, possa colocar em evidência a perspectiva adotada pelos autores e sua preocupação com a apresentação da língua enquanto fenômeno flexível e multifacetado.

\section{Da seleção dos critérios e dos livros didáticos à realização das análises}

Tendo em vista que os efeitos do estilo linguístico podem se refletir em diferentes planos, como o fonológico, o morfossintático, o semântico, o lexical, entre outros, e diante da impossibilidade de focalizar todos esses planos na mesma medida, partimos das obras de referência Introduzione alla linguistica italiana de Sobrero e Miglietta, lançada

5. No Brasil, devido ao número restrito de escolas públicas que contemplam a língua italiana em seu currículo, optamos por estudar a visão de língua normalmente difundida em livros didáticos usados em instituições de ensino privadas, já que esse constitui o principal contexto de difusão de língua italiana no Brasil (ITÁLIA, 2019, p. 11) 
em 2007, e Le varietà dell'italiano, de Coveri et al., publicada em 1998, e selecionamos 16 critérios - 7 capazes de identificar o registro formal e 9 , o registro informal.

Os sete fenômenos linguísticos associados ao registro formal foram os seguintes:

1. circunlocuções;

2. conectivos elaborados;

3. escassas referências ao "eu" falante;

4. léxico dos subcódigos;

5. palavras áulicas;

6. tendência ao desenvolvimento argumentativo;

7. variantes morfológicas formais.

Dessa maneira, procuramos nos livros didáticos os seguintes elementos no plano lexical: léxico dos subcódigos, isto é, vocabulário técnico-científico, como os termos usados nos campos da medicina, informática, linguística, entre outros; palavras áulicas; conectivos elaborados, ou seja, conjunções compostas, como affinché [a fim de que], oppure [ou], sebbene [embora], ou locuções conjuntivas, como dal momento che [a partir do momento em que], ciò nonostante [não obstante isso], etc.

Examinamos também a presença de variantes morfológicas formais, como o emprego do alocutivo, Lei, que, diferentemente da segunda pessoa $t u$, é utilizada somente em situações formais, quando não há grau de familiaridade ou relação de amizade entre os interlocutores ou, ainda, quando existe relação hierárquica entre eles.

Finalmente, buscamos identificar se, nos diálogos, havia circunlocuções; se era possível perceber uma tendência argumentativa nos conteúdos dos livros e se havia certo esforço por parte do falante em diminuir a frequência das referências a si próprio.

É importante destacar que, embora tenhamos optado por tomar como base obras clássicas da sociolinguística italiana, reconhecemos que elas partem, muitas vezes, das impressões dos linguistas que as escrevem, os quais aproximam demasiadamente o registro formal da modalidade escrita, como se a formalidade estivesse circunscrita a textos argumentativos escritos em terceira pessoa. 
Apesar de não concordarmos com essa visão, na medida em que entendemos que o registro formal não pode ser confundido com textos escritos, decidimos, mesmo assim, nos basear nessas obras e nesses critérios, pois consideramos que a maioria deles poderia nos auxiliar na diferenciação entre um extremo do continuum e outro.

Quanto aos critérios atinentes ao registro informal, foram selecionados os seguintes traços:

1. emprego do sufixo -ata;

2. emprego do sufixo -issimo com substantivos;

3. emprego elevado de diminutivos;

4. epítetos e imprecações;

5. estrutura centrada no "eu" falante;
6. formas onomatopaicas;

7. mínima explicitação sintática;

8. palavras abreviadas;

9. verbos bipronominais

Nas descrições dos registros linguísticos encontradas nas obras consultadas, assume-se que, em produções linguísticas mais informais, os falantes tenderiam a contar mais suas experiências pessoais, constituindo-se como centro da comunicação. Dessa maneira, eles usariam mais a primeira pessoa do singular e empregariam mais frequentemente epítetos e imprecações, como reflexo da maior liberdade e intimidade que têm com o interlocutor.

Nessas interações, haveria também: verbos bipronominais, como cavarsela, farcela, prendersela, andarsene, usados no lugar dos verbos reflexivos ou intransitivos, respectivamente: arrangiarsi [arranjar-se], riuscire [conseguir], preoccuparsi [preocupar-se], partire [partir, ir embora], preferidos em contextos menos familiares; extensão do uso do sufixo -issimo a substantivos, quando a norma italiana prevê sua ocorrência apenas com adjetivos, como em: macchinissima [carríssimo], donnissima [mulherzíssima], que expressam ironicamente a qualidade máxima do substantivo alterado; utilização frequente de diminutivos afetuosos e formas onomatopaicas como em casetta e dlin dlon, respectivamente; emprego do sufixo -ata em palavras que já possuem conotação negativa, adquirindo maior valor pejorativo, como em porcata [porcaria] e stupidata [estupidez].

Ainda no interior do polo da informalidade, haveria maior uso de palavras abreviadas e menor explicitação das relações sintáticas entre 
as orações, com ocorrências mais frequentes de orações coordenadas assindéticas.

Tendo definido os critérios que guiaram a análise, explicitaremos a seguir os fatores que motivaram a seleção dos livros didáticos analisados.

Em $2010^{6}$, foi realizado um levantamento que se baseou no envio de um questionário a vinte instituições paulistas, dentre as quais, algumas são escolas de línguas e outras são associações que oferecem aulas de italiano. Nele perguntamos qual era o livro didático adotado nos cursos. Com as respostas fornecidas, geramos o seguinte gráfico:

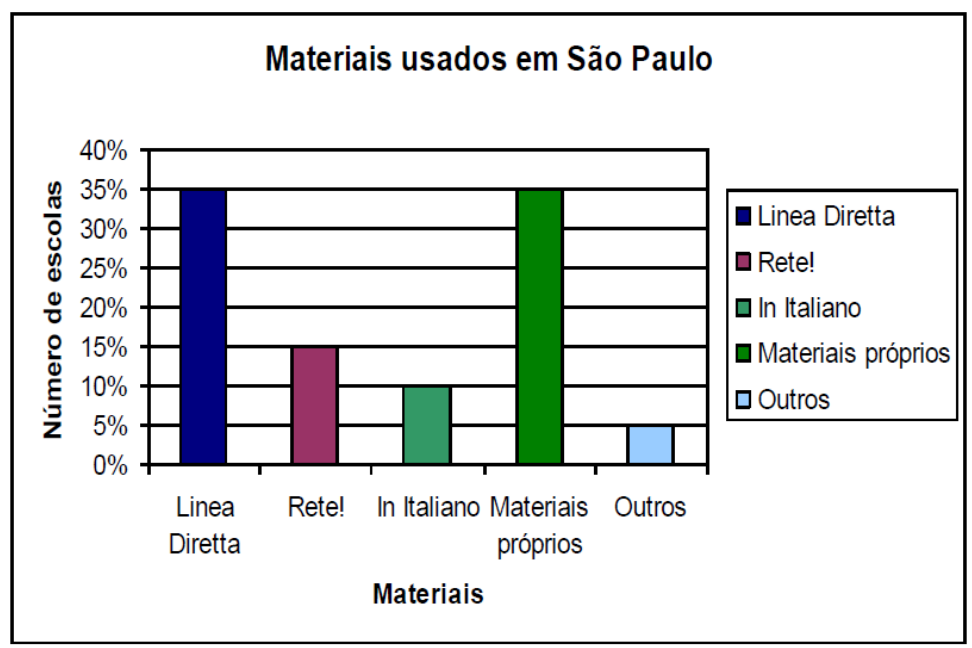

Gráfico 1 - Materiais usados no estado de São Paulo em 2010

A partir desses dados, fica evidente o grande número de instituições que optam por usar material didático próprio ( 7 das 20 instituições de ensino que nos responderam). Essa constatação, embora mereça ser

6. É importante ressaltar que, passados cerca de nove anos da realização desse levantamento inicial, provavelmente, as coleções adotadas pelas escolas investigada não são mais as mesmas. Contudo, considerando nossa experiência com livros didáticos publicados recentemente, como Nuovo Espresso, Nuovo Progetto, Arrivederci, entre outros, é possível dizer que o cenário continua o mesmo e que os problemas aqui delineados continuam sendo apresentados mesmo em obras atuais. 
mais bem compreendida e aprofundada em oportunidades futuras, foi descartada em nosso estudo, uma vez que o recorte de análise se baseou em livros empregados em maior escala. Desse modo, foram selecionadas as duas coleções utilizadas pelo maior número de escolas: Linea Diretta e Rete!.

O primeiro desses livros foi escrito por Conforti e Cusimano. A primeira edição, nomeada somente Linea Diretta, publicada primeiramente na Alemanha, data de 1994 e é constituída por dois volumes de livros do aluno, dois volumes de livros de exercícios, dois CDs de áudio e dois manuais do professor, um para cada volume.

Em 2005, a coleção sofreu algumas modificações: o primeiro volume, Linea Diretta 1, foi dividido em Linea Diretta nuovo $1 a$ e $1 b$ (doravante LD1a e LD1b). Com essa mudança, os livros de exercícios do antigo Linea Diretta 1, que eram vendidos em um volume separado, passaram a integrar os dois volumes de livro do aluno e apenas o Linea Diretta 2 (doravante LD2) continuou com a formatação antiga, ou seja, um livro do aluno e um livro de exercícios vendidos separadamente. As ilustrações a seguir apresentam a capa dos três volumes resultantes desse processo:
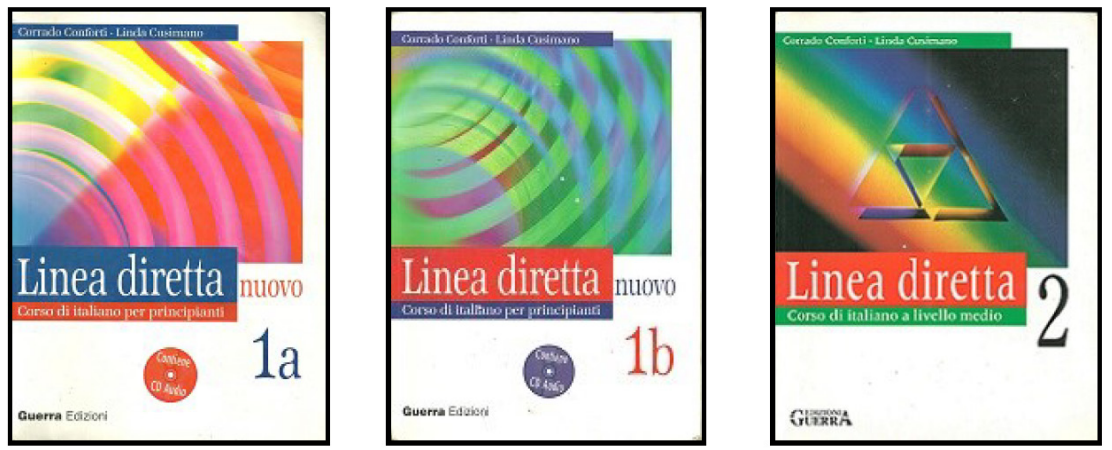

Figura 1 - Capas dos três volumes do manual LD

A coleção é estruturada em 31 unidades, distribuídas da seguinte maneira: oito lições no LD1a, oito no LD1b e quinze no LD2.

A segunda coleção - Rete! - foi lançada em 2000, com a autoria de Mezzadri e Balboni. Assim como o LD, Rete! é formado por três 
volumes, Rete!1 (R!1), Rete!2 (R!2) e Rete!3 (R!3). A cada volume do livro do aluno corresponde um livro de exercícios, destinado ao estudo individual. A coleção conta com CDs de áudio, que contêm alguns dos diálogos presentes no livro do aluno e com os volumes de guia do professor. A seguir, reproduzimos as capas dos três volumes de livro do aluno dessa coleção:
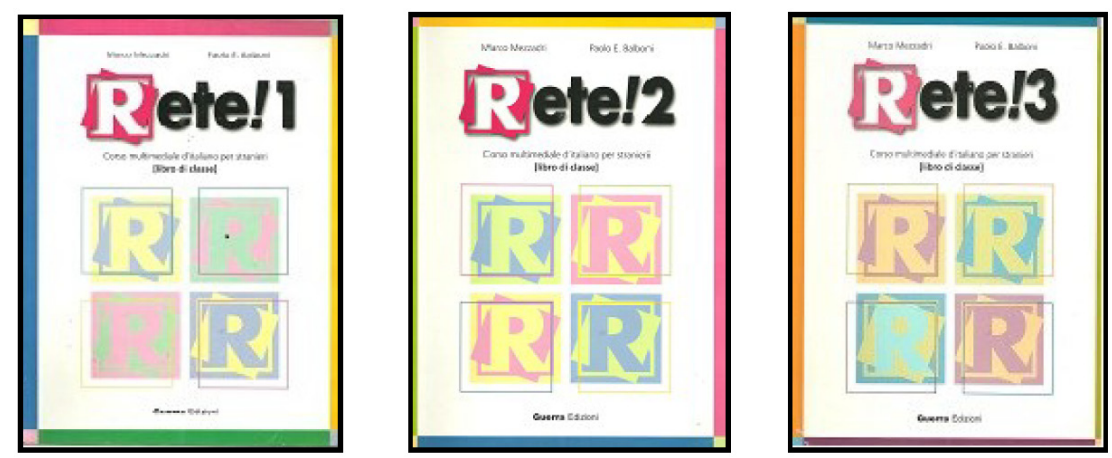

Figura 2 - Capas dos três volumes do $R$ !

O número de unidades nos dois primeiros volumes é o mesmo, quinze, enquanto o terceiro livro é formado por dez unidades, totalizando assim 40 unidades.

Tendo em vista o nosso objetivo de analisar se e como se dá a abordagem da variação diafásica nessas duas coleções, passaremos a descrever as etapas cumpridas.

A análise dos manuais se deu a partir de duas perspectivas distintas: uma que procurava verificar se os livros selecionados tratavam explicitamente as variedades linguísticas, fazendo menção direta a elas e apresentando-as, inclusive, metalinguisticamente; e outra concentrada na identificação de instruções mais implícitas, que levassem os aprendizes a refletir quanto a fenômenos marcados em diafasia, através, por exemplo, da inserção desses traços nos diálogos.

Para fazer o exame daquilo que era explicitamente tratado, foram observados todos os momentos em que explicações eram dirigidas aos aprendizes, no livro do aluno e no de exercícios, e aos docentes, no guia do professor. 
As explicitações acerca da dimensão diafásica podiam ser tanto citações diretas ao nome de uma determinada variedade quanto alusões indiretas a um fenômeno atribuído a uma dada variedade. Além disso, baseados em Bell (1984), procuramos menções que nos pudessem fornecer indícios de como os autores das coleções diferenciam contextos formais de informais, procurando entender quais fatores, segundo eles, entrariam em jogo no momento da seleção do registro linguístico.

Com relação à perspectiva implícita, examinamos todos os diálogos contidos nas duas obras, uma vez que, tendencialmente, poderiam conter um número maior de variantes linguísticas marcadas em diafasia justamente por reproduzirem a língua falada em situações comunicativas teoricamente variadas.

Essa escolha foi motivada, além disso, pelo fato de termos notado que os diálogos constituem o ponto basilar da unidade, já que são projetados artificialmente para conter os elementos estruturais e lexicais que devem ser ensinados ao longo das aulas, como deixa evidente o trecho a seguir, extraído do LDla:

Gli esercizi successivi a questi dialoghi, e che dei dialoghi mettono in evidenza le forme, hanno la funzione di far apprendere allo studente le strutture grammaticali,le regole sintattiche, le espressioni necessarie alla realizzazione di determinate intenzioni comunicative, nonché l'esatta pronuncia e la corretta intonazione necessarie ad esprimersi. (LD1a, p. 7) ${ }^{7}$

Quando os autores dizem que os exercícios "colocam em evidência as formas dos diálogos", permitem entrever que esses últimos são estruturados exatamente para que sejam portadores de novos conteúdos e, mais que isso, para que constituam o cerne das unidades didáticas, já que eles serão a base para que, por meio de quadros de reflexão metalinguística e de exercícios, sejam ensinadas "as estruturas gramaticais,

7. Todas as traduções presentes no artigo são de nossa autoria: “os exercícios posteriores a esses diálogos, que colocam em evidência as formas dos diálogos, têm a função de ensinar ao estudante as estruturas gramaticais, as regras sintáticas, as expressões necessárias para a realização de determinadas intenções comunicativas, e, também, a pronúncia exata e a correta entonação necessária para se expressar". 
as regras sintáticas, as expressões [...] e também a pronúncia exata e a correta entonação"s.

Apoiados nessas constatações, partimos da premissa de que, se existe qualquer preocupação por parte dos autores dos livros didáticos em apresentar a variação diafásica, então, seria de se supor que seus traços característicos deveriam estar presentes nos diálogos, uma vez que eles são o ponto central a partir do qual novos conteúdos são incorporados à unidade didática.

Assim, observamos todas as páginas dos seis volumes dos manuais analisados e coletamos 102 diálogos, divididos entre diferentes gêneros textuais, dentre os quais: telefonemas, conversas face a face, entrevistas, entrevistas de emprego, entre outros.

Dos 102 diálogos que formam o corpus de análise, 34 pertencem à série LD: 16 foram extraídos dos dois primeiros volumes (de cada um dos volumes foram retirados 8) e 18, do terceiro volume. Os demais 68 diálogos referem-se à série R!: 27 foram encontrados no primeiro volume, 32 no segundo e apenas 9 no terceiro.

É importante esclarecer que, coletando os diálogos na série R!, deparamo-nos com alguns diálogos escritos, isto é, diálogos que foram inseridos na série apenas como uma "imitação" de gêneros da oralidade, mas que não são, em nenhum momento, "falados" e "ouvidos". A função desses diálogos, diferentemente da função dos gêneros orais em nossa vida cotidiana, está ligada à habilidade de leitura e não à de audição. Contudo, não obstante saibamos que esse tipo de diálogo artificial não exista senão no manual didático, decidimos considerá-los em nossa análise, visto que eles tendem a refletir, talvez mais até do que os diálogos interpretados por atores profissionais, as preocupações dos autores, podendo potencialmente fornecer dados relevantes quanto àquilo que se pretende (ou não) apresentar aos aprendizes.

8. Os autores partem de uma visão normativa de língua ao afirmarem que os diálogos devem apresentar "a pronúncia exata" da língua italiana, mas em nenhum momento esclarecem à qual variedade tal pronúncia corresponderia, além disso, assumem que a pronúncia não "exata", deve ser excluída do ensino, mostrando desalinhamento com uma visão de língua não normativa. 


\section{Há lugar para os registros linguísticos nos livros didáticos italianos?}

A partir da análise de todos os diálogos contidos nos manuais, encontramos um cenário bastante modesto, em que poucas ocorrências de fenômenos marcados como formais foram identificados. A tabela a seguir deixa clara a exiguidade dos resultados:

Tabela 1 - Resultados referentes ao registro formal nos diálogos

\begin{tabular}{l|c|c|c|c|c|c|c|c}
\hline & LD1a & LD1b & LD2 & $\mathbf{\%}$ & $\mathbf{R ! 1}$ & $\mathbf{R ! 2}$ & $\mathbf{R} ! \mathbf{3}$ & $\mathbf{\%}$ \\
\hline Circunlocuções & $1 / 8$ & $3 / 9$ & $1 / 18$ & $14 \%$ & $3 / 27$ & $1 / 32$ & $0 / 9$ & $6 \%$ \\
\hline Conectivos elaborados & $0 / 8$ & $1 / 9$ & $4 / 18$ & $14 \%$ & $6 / 27$ & $1 / 32$ & $4 / 9$ & $16 \%$ \\
\hline Escassas referências ao "eu” falante & $1 / 8$ & $1 / 9$ & $4 / 18$ & $17 \%$ & $4 / 27$ & $6 / 32$ & $1 / 9$ & $16 \%$ \\
\hline Léxico dos subcódigos & $0 / 8$ & $2 / 9$ & $0 / 18$ & $6 \%$ & $2 / 27$ & $2 / 32$ & $2 / 9$ & $9 \%$ \\
\hline Palavras áulicas & $0 / 8$ & $0 / 9$ & $0 / 18$ & $0 \%$ & $0 / 27$ & $0 / 32$ & $0 / 9$ & $0 \%$ \\
\hline $\begin{array}{l}\text { Tendência ao desenvolvimento } \\
\text { argumentativo }\end{array}$ & $0 / 8$ & $2 / 9$ & $10 / 18$ & $34 \%$ & $2 / 27$ & $1 / 32$ & $2 / 9$ & $7 \%$ \\
\hline Variantes morfológicas formais & $5 / 8$ & $3 / 9$ & $6 / 18$ & $40 \%$ & $10 / 27$ & $10 / 32$ & $2 / 9$ & $32 \%$ \\
\hline
\end{tabular}

Uma leitura horizontal dos dados revela que nenhum fator chega a atingir um percentual alto, independentemente do livro didático considerado. Além disso, é possível notar a ausência completa do critério "palavras áulicas", assim como chamam a atenção as frequências bastante baixas de fenômenos tais quais: as circunlocuções, os conectivos elaborados e o léxico dos subcódigos.

Além disso, identificamos uma forte tendência de os diálogos serem construídos em primeira pessoa do singular, isto é, são poucas as interações nas quais se abre espaço para narrativas de eventos ocorridos a terceiros. De fato, tanto no LD quanto no R!, aproximadamente $83 \%$ dos diálogos se referem a fatos vivenciados pelo próprio sujeito falante.

No livro LD, foi registrada a presença de textos argumentativos em $34 \%$ dos diálogos. No geral, trata-se de situações do cotidiano, como a interação entre um vendedor e um cliente em uma loja de calçados, na qual o vendedor procura convencer seu cliente da alta qualidade de um dos sapatos por ele vendido (segunda unidade do LD2). No livro $\mathrm{R}$ !, por outro lado, não vimos essa tendência, o que distancia as duas coleções quanto a esse critério. 
No que diz respeito ao critério que alcançou índices percentuais mais altos, vemos que, em ambos os livros, ele correspondeu à inserção de variantes morfológicas formais, encontrada em um número considerável de diálogos, $40 \%$ no LD e $32 \%$ no R!. Nessas interações, foram identificadas passagens nas quais se confiava ao alocutivo Lei a função de marcador de relação social na qual havia distanciamento entre os interlocutores. O exemplo a seguir foi retirado do quarto diálogo do LD1a. Trata-se de um pedido de informação: uma turista italiana, em Roma, pede a um guarda de trânsito como chegar ao Palazzo Spada:

Turista: Eh, senta scusi!

Vigile: Buongiorno, mi dica!

Turista: Buongiorno. Mi scusi, mi sa dire dov'è

Piazza Capo di Ferro?

Vigile: Piazza Capo di Ferro. Si, senta, ma Lei

è a piedi?

Turista: Sì, sono a piedi. ${ }^{9}$

No trecho acima, os verbos e o pronome sublinhados evidenciam o uso da terceira pessoa do singular como forma de tratamento cortês, requeridos, nesse contexto, para sinalizar o respeito e a cortesia entre os personagens.

Em R!, como dissemos, o cenário identificado não se distancia muito daquele encontrado em $\mathrm{LD}$, e também nessa série o fenômeno mais amplamente inserido é o emprego de elementos morfológicos relacionados ao alocutivo Lei.

Levando em consideração que os livros didáticos teriam que trazer em seus últimos volumes textos cada vez mais complexos em conformidade com o grau mais alto de competência comunicativa dos aprendizes, esperávamos que, comparando os números encontrados nos diferentes volumes dos manuais, veríamos uma progressão sistemática na frequência de inserção de fenômenos relacionados à diafasia. No entanto, através do confronto dos volumes, diagnosticamos que, no LD, dos sete parâmetros procurados, apenas três são encontrados mais

9. T: Eh, escuta, com licença! / G: Bom dia, me diga! / T: Bom dia, com licença, o senhor sabe me dizer onde é a Praça Capo di Ferro? / G: Praça Capo di Ferro. Sim, escuta, mas a senhora está a pé? / T: Sim, estou a pé. 
no último volume, sendo que esse número mais alto de ocorrências não parece refletir maior cuidado com a variação, pois os aspectos não são retomados nas explicações e atividades subsequentes. Já em R!, nenhum fenômeno diafásico passa a ser mais abordado na parte final do curso, pelo contrário, quatro deles têm seus números diminuídos no terceiro livro.

Em face desses resultados, parece coerente dizer que a familiaridade com fatores ligados ao registro formal não é fomentada no decorrer do curso, pelo menos do ponto de vista implícito, ou seja, através do contato com os diálogos disponíveis nas obras.

Os números encontrados permitem-nos dizer que o tratamento do registro formal em ambos os manuais se resume ao oferecimento de diálogos em que há elementos morfossintáticos ligados à chamada forma de cortesia, enquanto outros elementos também importantes para a caracterização do registro parecem ser negligenciados.

No que diz respeito às sugestões e explicações direcionadas aos docentes, no guia do professor, e aos discentes, no livro do aluno, pudemos constatar que $\mathrm{R}$ ! conserva a inclinação ao tratamento da segunda e da terceira pessoa do singular como praticamente único elemento diferenciador dos registros. Nesse sentido, dos 22 trechos que fazem referência à diafasia, 10 se baseiam na contraposição $t u \times$ Lei, como exemplificam os dois excertos abaixo, retirados, respectivamente, do livro de classe e do guia do professor do primeiro volume:

1) Esercizio 3 - quale dialogo è formale e quale informale?

In italiano si usa tu in situazioni informali, in situazioni formali si usa Lei (R!1, p. 16)

2) È fondamentale che gli studenti colgano le nozioni di "formale" $e$ "informale"; ci sono forse più problemi per gli studenti anglofoni che non distinguono la formalità con un pronome, o con quelli ispanofoni e lusofoni che usano pronomi speciali per la formalità [sic]. (R!1, p. 14) $)^{10}$

10. 1) Exercício 3 - qual diálogo é formal e qual informal? Em italiano se usa "tu" em situações informais, em situações formais se usa "Lei".

2) É fundamental que os estudantes compreendam as noções de "formal" e "informal"; existem talvez mais problemas para os estudantes falantes de inglês, que não distinguem a formalidade com um pronome, que para aqueles que falam espanhol e português que usam pronomes especiais para a formalidade. 
No primeiro trecho, propõe-se que o aprendiz leia os diálogos transcritos no livro e que julgue se são interações formais ou informais. Logo na sequência, são dadas orientações que o guiam nessa identificação, como exatamente a utilização dos pronomes pessoais do caso reto tu, em caso de informalidade, e Lei, em caso de formalidade.

Já o segundo excerto, dirigido aos docentes, inicia-se com uma sugestão mais geral, segundo a qual os professores devem estar atentos ao tratamento das noções de formal e informal, criando a expectativa de que esses conceitos seriam mais bem definidos em seguida. No entanto, o que ocorre, mais uma vez, é a vinculação desses dois conceitos à escolha do pronome, como se esse fosse o único elemento linguístico capaz de distinguir os registros linguísticos.

Quanto aos demais elementos contemplados explicitamente, pudemos observar no livro do aluno as seguintes ocorrências: a) comentário acerca do emprego do pronome loro [eles] - terceira pessoa do plural - no lugar de voi [vós] - segunda pessoa do plural - em contextos extremamente formais; b) alusão ao emprego das saudações finais distinti/cordiali saluti [saudações cordiais], como cumprimentos corteses e formais; c) explicação sobre a utilização de verbos no condicional para a formulação de pedidos mais gentis; e d) apresentação dos verbos andare [ir] - usado em situações mais informais - e recarsi [dirigir-se], em contextos formais.

No guia do professor, todas as indicações são para que o docente esteja atento ao registro empregado pelo aluno, como no excerto a seguir, extraído do R!2:

Incoraggi a far molta attenzione agli aspetti legati al registro (formale) informale) sia da un punto di vista lessicale o funzionale che da quello dell'intonazione [...] (R!2, p. 10) $)^{11}$

Chama-nos a atenção o fato de o livro enfatizar de maneira tão incisiva essa recomendação ao professor em pelo menos quatro outras oportunidades, mas não procurar definir de maneira mais clara o que entende por registro, tampouco oferecer uma explicação mais aprofun-

11. Motive a prestar muita atenção aos aspectos ligados ao registro (formal/informal) tanto de um ponto de vista lexical ou funcional quanto do ponto de vista da entonação [...]. 
dada de quais fatores extralinguísticos (audiência, assunto, ambiente) norteariam a opção por um ou outro estilo, ou ainda esclarecer quais seriam os elementos de cunho lexical ou funcional ao qual esse profissional deveria estar atento. Sendo assim, a nosso ver, o livro acaba por exigir uma postura do professor, sem que antes lhe tenham sido dadas ferramentas apropriadas.

Considerando as recomendações dirigidas aos professores e as explicações fornecidas aos aprendizes pelo $\mathrm{LD}$, temos uma redução ainda maior do número de elementos tratados. Foram encontrados 17 excertos nos quais se mencionam, ainda que rapidamente, fenômenos relacionados ao estilo. Desse total, 11 se limitavam a contrastar a segunda pessoa do singular ( $t u$ à terceira (Lei), enquanto os 6 restantes abordavam outras questões, como: a) o uso do pronome demonstrativo questo [esse] em situações informais; b) o emprego de pure [também] como elemento ligado à cortesia; c) a distinção entre voi [vós] e loro [eles]; e d) a apresentação do condizionale semplice [futuro do pretérito] em alternativa ao presente do indicativo [presente do indicativo] na formulação de pedidos corteses.

Com isso, fica evidente que as obras investigadas, além de raramente tratarem traços do registro formal, fazem-no a partir de uma perspectiva bastante superficial. Isso se confirma quando constatamos que, dos sete critérios observados por nós, apenas o último - "variantes morfológicas formais" - é retomado sistematicamente por meio de recomendações e explicações.

Voltando-nos nesse momento aos critérios do registro informal, identificamos os seguintes elementos:

Tabela 2 - Resultados referentes ao registro informal nos diálogos

\begin{tabular}{l|l|l|l|l|l|l|l|l}
\hline & LD1a & LD1b & LD2 & $\mathbf{\%}$ & $\mathbf{R} ! \mathbf{1}$ & $\mathbf{R} ! \mathbf{2}$ & $\mathbf{R} ! \mathbf{3}$ & $\mathbf{\%}$ \\
\hline $\begin{array}{l}\text { Emprego do sufixo -ata (como em stupidata } \\
\text { e porcata) }\end{array}$ & $0 / 8$ & $0 / 9$ & $0 / 18$ & $0 \%$ & $0 / 27$ & $1 / 32$ & $0 / 9$ & $1,5 \%$ \\
\hline $\begin{array}{l}\text { Emprego do sufixo -issimo também com } \\
\text { substantivos (como em donnissima ou } \\
\text { macchinissima) }\end{array}$ & $0 / 8$ & $0 / 9$ & $0 / 18$ & $0 \%$ & $0 / 27$ & $0 / 32$ & $0 / 9$ & $0 \%$ \\
\hline Emprego elevado de diminutivos & $2 / 8$ & $4 / 9$ & $9 / 18$ & $43 \%$ & $0 / 27$ & $0 / 32$ & $1 / 9$ & $1,5 \%$ \\
\hline Epítetos e imprecações & $0 / 8$ & $0 / 9$ & $1 / 18$ & $3 \%$ & $0 / 27$ & $0 / 32$ & $0 / 9$ & $0 \%$ \\
\hline Estrutura centrada no "eu" falante & $7 / 8$ & $7 / 9$ & $14 / 18$ & $80 \%$ & $22 / 27$ & $24 / 32$ & $6 / 9$ & $76 \%$ \\
\hline
\end{tabular}




\begin{tabular}{l|l|l|l|l|l|l|l|l}
\hline & LD1 a & LD1b & LD2 & $\mathbf{\%}$ & $\mathbf{R} ! \mathbf{1}$ & $\mathbf{R} ! \mathbf{2}$ & $\mathbf{R} ! \mathbf{3}$ & $\mathbf{\%}$ \\
\hline $\begin{array}{l}\text { Formas onomatopaicas (como em cin cin ou } \\
\text { dlen dlen) }\end{array}$ & $1 / 8$ & $0 / 9$ & $1 / 18$ & $6 \%$ & $0 / 27$ & $0 / 32$ & $0 / 9$ & $0 \%$ \\
\hline Pronomes tônicos e átonos & $5 / 8$ & $7 / 9$ & $18 / 18$ & $86 \%$ & $13 / 27$ & $31 / 32$ & $9 / 9$ & $78 \%$ \\
\hline Mínima explicitação sintática & $6 / 8$ & $9 / 9$ & $4 / 18$ & $54 \%$ & $24 / 27$ & $23 / 32$ & $5 / 9$ & $76 \%$ \\
\hline Palavras abreviadas & $0 / 8$ & $0 / 9$ & $0 / 18$ & $0 \%$ & $0 / 27$ & $1 / 32$ & $0 / 9$ & $0 \%$ \\
\hline $\begin{array}{l}\text { Verbos bipronominais (como cavarsela, } \\
\text { farcela, } \text { etc.) }\end{array}$ & $1 / 8$ & $3 / 9$ & $4 / 18$ & $23 \%$ & $1 / 27$ & $3 / 32$ & $1 / 9$ & $7 \%$ \\
\hline
\end{tabular}

Assim como aconteceu quanto aos traços do registro formal, a busca orientada pelos critérios acima citados produziu percentuais baixos. No entanto, na comparação entre uma série didática e outra, vê-se que LD tende a contemplar um número um pouco maior de fenômenos:

1. emprego elevado de diminutivo (43\%)

2. mínima explicitação sintática (54\%)

3. estrutura centrada no "eu" falante $(80 \%)$

4. frequentes pronomes tônicos e átonos $(78 \%)$

O livro R!, por sua vez, apresenta números altos para três fenômenos:

1. mínima explicitação sintática (76\%);

2. estrutura centrada no "eu" falante $(76 \%)$;

3. frequentes pronomes tônicos e átonos $(78 \%)$.

Embora os dois manuais apresentem fenômenos ligados ao registro informal, percebemos um aspecto fundamental: tanto em LD quanto em R! são introduzidos elementos linguísticos que não parecem ser as marcas mais patentes desse registro, enquanto são excluídas as marcas mais estigmatizadas. Prova dessa tendência é o fato de que os fenômenos pouco tratados em ambas as séries são:

1. o emprego do sufixo - ata: não encontrado no LD e presente em $1,5 \%$ do corpus do R!;

2. os epítetos e imprecações: presentes no LD em 3\% dos diálogos e ausentes no R!;

3. as formas onomatopaicas: presentes no LD em $6 \%$ do corpus e inexistentes no R!;

4. as palavras abreviadas: não identificadas nos manuais;

5. o emprego do sufixo -issimo com substantivos: não identificado nos manuais. 
Quando nos diálogos foram procuradas ocorrências do sufixo -ata, foi encontrado apenas um exemplo, no diálogo 1 de R!2, no qual se diz: "Perfetta?! Non dire stupidate” [Perfeita?! Não diga coisas estúpidas], formado pelo acréscimo do sufixo - ata ao adjetivo stupido.

Após essa inserção, porém, não há nenhum tipo de explicação quanto ao fato de que esse sufixo constitui uma produtiva e recente inovação lexical, tampouco quanto ao seu significado como "operação típica de" (stupidate estaria para ação típica de pessoa estúpida), que pode se formar também a partir de substantivos próprios, como em: "berlusconata, lucherinata, storacinata" (CORTELAZZO, 2000, p. 200), provenientes, respectivamente, das personalidades italianas Berlusconi, Lucherini e Storace.

No que concerne aos epítetos e imprecações, encontramos apenas um exemplo no diálogo 15 de LD2. Na situação evidenciada, um casal discute, e a esposa a certa altura diz: "Se te l'avessi detto prima, non sarebbe cambiato proprio nulla, perché ti saresti visto lo stesso questa maledetta partita" [Se tivesse te falado antes não teria mudado nada, porque você teria assistido do mesmo jeito esse maldito jogo]. Trata-se do único momento no qual se identifica o aparecimento de uma unidade lexical que pode ser considerada imprecação. Observamos, todavia, que os autores do livro didático não parecem considerá-la como elemento a ser abordado em sala de aula, pois não retomam nem tematizam sua presença em nenhum dos livros que compõem a série.

Quanto às onomatopeias, em LD aparecem duas vezes, uma vez no primeiro diálogo do primeiro volume, quando um grupo de conhecidos faz um brinde emitindo a típica onomatopeia para essas ocasiões, "cincin”, inclusive já lexicalizada; e a segunda vez, no terceiro volume, quando, em uma conversa entre amigos, um deles narra um acontecimento de sua vida e diz: "L'allarme esattamente, ha cominciato a suonare, dlen, dlen, dlen, dlen, dlen, così" [o alarme exatamente, começou a tocar, dlen, dlen, dlen, dlen, dlen, assim]. Mais uma vez, não obstante tais inserções, não há explicitações quanto à sua função e significado em conversas informais, tampouco quanto a possíveis contextos de uso.

Na série R!, identificamos a situação oposta, isto é, não há, no corpus constituído pelos diálogos, onomatopeias, mas há um comen- 
tário a respeito desse fenômeno na nona unidade do livro de classe do terceiro volume:

Sono tante le parole onomatopeiche che si usano nella vita di tutti i giorni. A volte sono uguali o molto simili in varie lingue. Il linguaggio dei bambini, quello dei fumetti, ma anche certa poesia ne sono molto ricchi, te ne presentiamo alcuni tra i più usati [sic] (R!3: LA, p. 98) ${ }^{12}$

Nessa passagem, os autores relacionam as onomatopeias à língua de todos os dias, mas não especificam sua colocação no registro informal. De qualquer maneira, parece relevante a preocupação demonstrada e o fato de terem sido inseridas como objeto a ser ensinado. De fato, a citação acima precede um exercício específico no qual os aprendizes devem ligar onomatopeias a sons emitidos por animais ou objetos.

Ademais, no livro R! chama-se a atenção para o uso do verbo rimorchiare [literalmente rebocar] como alternativa "menos educada" à forma abbordare [abordar] (R!2, p. 28) e é inserida a indicação de un sacco como equivalente informal de molto [muito] na descrição dos aspectos informais.

No livro LD, não encontramos nenhuma orientação acerca do registro informal, nem nas explicações aos discentes nem naquelas aos docentes, o que mostra que LD, se por um lado, insere nos diálogos marcas do registro informal, ainda que se concentre nas pouco estigmatizadas, por outro, desperdiça a oportunidade de aprofundar o conhecimento dos aprendizes sobre esses fenômenos, não incorporando atividades que os contemplem.

Somado a essas lacunas, em nenhum dos livros são propostas atividades em que o aprendiz seja chamado a pensar no papel da formalidade na cultura italiana, ou seja, não lhe são oferecidas oportunidades para refletir sobre as razões que levam um falante italófono a optar por um estilo mais ou menos formal, tampouco se estimulam discussões sobre as relações instauradas entre falantes e audiência e sobre como esses elementos extralinguísticos se refletem no plano linguístico (Bell, 1984).

12. São tantas as palavras onomatopaicas que são usadas na vida de todos os dias. Às vezes, são iguais ou muito semelhantes em várias línguas. A linguagem das crianças, a dos gibis, mas também certa poesia é muito rica. Apresentamos a você algumas entre as mais usadas. 
Dessa maneira, constatamos que a complexidade envolvida na definição do registro linguístico descrita por Bell (1984), assim como os fenômenos característicos dessa dimensão elencados por Sobrero e Miglietta (2007) e Coveri et al. (1998) são praticamente excluídos dos livros didáticos analisados, sendo tratados raramente, superficialmente e como algo limitado quase exclusivamente à seleção das formas de tratamento.

\section{Considerações finais}

Neste artigo, colocamos como objetivo central a reflexão acerca do lugar dos registros linguísticos em dois livros didáticos de italiano para estrangeiros, Linea diretta e Rete!, procurando compreender se e em que medida os guias do professor e os livros de classe orientam docentes e aprendizes.

Ao longo das análises, ficou evidente que, nos diálogos das obras analisadas, são inseridos poucos fenômenos ligados ao registro formal, com exceção da escolha pelo alocutivo Lei, reiterada em diversos momentos em ambos os manuais.

Sob a ótica explícita, nos guias do professor e nos livros do aluno, diagnosticamos a insistência no tratamento desse traço como principal elemento representante do registro formal. Outrossim, visualizamos algumas breves alusões a características como: distinção entre voi e loro; cumprimentos corteses como distinti saluti, diferença semântica entre os pares andare e recarsi, rimorchiare e abbordare; e distinção no uso do condizionale semplice em oposição ao presente indicativo na formulação de pedidos, porém de modo casual e pouco aprofundado.

No que tange ao polo da informalidade, constatamos que os diálogos em LD inserem quase os mesmos fenômenos que R!, mas que ambos tendem a abordar traços não estigmatizados, evitando as imprecações e os epítetos, os sufixos -issimo e-ata e as palavras abreviadas.

Na perspectiva explícita, R! revela maior cuidado com essa dimensão da variação, já que incorpora explicações e atividades com foco em certos fenômenos informais, como as onomatopeias. LD, por sua vez, não oferece nenhuma orientação sobre elementos do registro informal. 
O fato de os livros terem praticamente excluído as marcas da formalidade e de terem adotado o emprego do alocutivo Lei como um dos poucos traços distintivos do registro formal nos leva a crer que seus autores partem do pressuposto equivocado de que esse único fator seria suficiente para permitir que o aprendiz produza e compreenda enunciados pertencentes a essa variedade, o que, a nosso ver, pode comprometer seriamente o desenvolvimento de sua competência sociolinguística.

Além disso, a ausência de propostas de interpretação textual que estimulem a reflexão sobre as relações estabelecidas entre falante e audiência mina a possibilidade de o aluno compreender os motivos que levam um falante a selecionar um registro mais ou menos formal. Dessa maneira, tendo apenas contato com a regra de que $t u$ é informal e Lei é formal, diminuem-se as chances de que o aprendiz se torne um falante capaz de produzir enunciados adequados a diferentes contextos, uma vez que ele não foi preparado para fazer a "leitura" de sua audiência, tampouco para ativar dispositivos linguísticos adequados aos seus objetivos.

Diante do exposto, fica evidente que esses livros didáticos não abordam de maneira suficiente a variação diafásica e que, portanto, novos livros didáticos devem ser formulados com vistas a abarcar essas variedades linguísticas e a prever atividades com foco em diferentes registros.

Enquanto essas mudanças não ocorrem, os agentes envolvidos no ensino de línguas devem estar atentos a essa dimensão, procurando informações em obras de referência como aquelas consultadas por nós, para que possa levar esse conteúdo à sala de aula, complementando os livros didáticos e oferecendo maior possibilidade de os aprendizes desenvolverem competência sociolinguística.

\section{Referências bibliográficas}

BAGNO, Marcos. 2007. Nada na língua é por acaso: por uma Pedagogia da variação linguística. São Paulo: Parábola Editorial.

BAGNO, Marcos; STUBBS, Michael; GAGNÉ, Gilles. 2002. Língua materna: letramento, variação \& ensino. São Paulo: Parábola.

BELL, Allan. 1984. Language style as audience design. Language in society, v. 13, n. 2, p. 145-204. 
BERRUTO, Gaetano. 1987. Sociolinguistica dell'italiano contemporaneo. Carocci: Roma.

BICKERTON, Derek. 1980. Creolization, linguistic universals, natural semantax and the brain. In: DAY, R. (Org.). Issues in English creoles. Heidelberg: Julius Groos Verlag.

BORTONI-RICARDO, Stella Maris. 2004. Educação em língua materna: a Sociolinguística em sala de aula. São Paulo: Parábola.

.2005. Nós cheguemos na escola, e agora?. São Paulo: Parábola Editorial.

CONFORTI, Corrado; CUSIMANO, Linda. 2005. Linea Diretta nuovo 1A: corso di italiano per principianti. Perugia: Guerra.

2005. Linea Diretta nuovo 1A: corso di italiano per principianti (Guida per l'insegnante). Perugia: Guerra. 2005. Linea Diretta nuovo 1B: corso di italiano per principianti. Perugia: Guerra.

2005. Linea Diretta nuovo 1B: corso di italiano per principianti (Guida per l'insegnante). Perugia: Guerra.

CONFORTI, Corrado; CUSIMANO, Linda. 1997. Linea Diretta nuovo 2: corso di italiano per principianti. Perugia: Guerra.

. 1997. Linea Diretta nuovo 2: corso di italiano per principianti (Guida per l'insegnante). Perugia: Guerra.

CORTELAZZO, Michele. 2000. Italiano d'oggi. Padova: Esedra.

COUPLAND, Nikolas. 1980. Style shifting in a Cardiff work setting. Language in society, v. 9, p. 1-12.

1981. The social differentiation on functional language use: a social investigation of travel agency talk. (Dissertation), University of Wales Institution of Science and Technology, Cardiff.

. 1984. Accommodation at work some phonological and their implications. International Journal of the sociology of language, v. 46. p. 49-70.

COVERI, Lorenzo; BENUCCI, Antonella; DIADORI, Pierangela. 1998. Le varietà dell'italiano: manuale di sociolinguistica italiana: con documenti e verifiche. Siena: Università per Stranieri di Siena/Roma: Bonacci.

CYRANKA, Lúcia F. M. 2011. Dos dialetos populares à variedade culta: a sociolinguística na escola. Curitiba: Appris.

D'ACHILLE, Paolo. 2006. L'italiano contemporaneo. Bologna: Mulino. FARACO, Carlos Alberto. 2008. Norma culta brasileira: desatando alguns nós. São Paulo, SP: Parábola Editorial.

HINDLE, Donald Morris. 1979. The social and situational conditioning of phonetic variation. (Dissertation). University of Pennsylvania, Philadelphia. 
HYMES, Dell H. 1962. The ethnography of speaking. In: GLADWIN, Thomas; STURTEVANT, William (eds.). Anthropology and human behavior. Washington, DC: American Anthropology Association, p. 13-53.

. 1966. On communicative competence. In: Research planning conference on language development in disadvantaged children. Nova York: Yeshiva University, Proceedings, p. 1-23. Disponível em: < https://files.eric.ed.gov/fulltext/ED027346.pdf > Acesso em 23 nov. 2019.

. 1972. On communicative competence. In: PRIDE; Holmes (eds.). Sociolinguistics: selected readings. Harmondsworth: Penguin, p. 269-293.

ITALIA. 2019. L'italiano nel mondo che cambia 2019. Disponível em: https://www.linguaitaliana.esteri.it/novita/documenti/content/70/ allegato.do. Acesso em 25 maio 2020.

LABOV, William. 1975. Le parler ordinaire. Paris: Ed. de Minuit.

. 2008. Padrões sociolinguísticos. Tradução Marcos Bagno; Maria T. Scherre; Caroline R. Cardoso. São Paulo: Parábola Editorial.

MEZZADRI, Marco; BALBONI, Paolo, E. 2000. Rete! 1: corso multimediale di italiano per stranieri. Perugia: Guerra Edizioni.

. 2001. Rete! 2: corso multimediale di italiano per stranieri. Perugia: Guerra Edizioni.

.2001. Rete! 2: corso multimediale di italiano per stranieri (Guida insegnante). Perugia: Guerra Edizioni.

.2001. Rete! 1: corso multimediale di italiano per stranieri (Guida insegnante). Perugia: Guerra Edizioni.

. 2002. Rete! 3: corso multimediale di italiano per stranieri. Perugia: Guerra Edizioni.

.2002. Rete! 3: corso multimediale di italiano per stranieri (Guida insegnante). Perugia: Guerra Edizioni.

SANTIPOLO, Matteo. 2002. Dalla sociolinguistica alla glottodidattica. UTET Università: Torino.

SILVA, Rita do C. P. 2009. A sociolinguística e a língua materna. Curitiba: Ibpex.

SOBRERO, Alberto A.; MIGLIETTA, Annarita. 2007. Introduzione alla linguistica italiana. 2. ed. Bari: Laterza.

THELANDER, Mats. 1982. A qualitative approach to the quantitative data of speech variation. In: ROMAINE, Suzanne (ed.). Sociolinguistic variation in speech community. London: Edward Arnold, p. 65-83. 